\title{
Use of rectifying meshes for active noise control in an air flow duct
}

\author{
Tsutomu Hoshino,* Tadashi Ohashi, ${ }^{* *}$ and Juro Ohga* \\ *Network System Laboratory, Fujitsu Laboratories Ltd., \\ L40, 4-1-1, Kamikodanaka, Nakahara-ku, Kawasaki, 211-8588 Japan \\ **Information Processing Administration Group, Fujitsu Limited, \\ C1334, 4-1-1, Kamikodanaka, Nakahara-ku, Kawasaki, 211-8588 Japan
}

(Received 12 October 1998)

\begin{abstract}
At the application of an Active Noise Control (ANC) for a duct with high speed flow whose velocity is around $12.0 \mathrm{~m} / \mathrm{s}$ (Reynolds number of $1.0 \times 10^{5}$ ), the following results for the use of the meshes, as the simplest method for rectifying the flow, were given. The effect of ANC depends on the disturbance velocity attenuation factor of the rectifying meshes. The meshes should not be installed closer to the detection sensor than half the diameter of the duct. The meshes are more effective than the use of thicker sound absorbent materials on the sensors, although the numerical aperture of duct cross-section can be decreased both. The noise reduction effect by use of the meshes were around 3 to $4 \mathrm{~dB}$, without $\mathrm{ANC}$ under $200 \mathrm{~Hz}$, and $13 \mathrm{~dB}$ of noise control effect at $500 \mathrm{~Hz}$ with the ANC system with the meshes (These effects were measured $100 \mathrm{~mm}$ from the duct outlet).
\end{abstract}

Keywords: Active noise control, Air flow, Duct, Rectifying meshes, Filtered-X algorithm

PACS number: 43. 50. Ki, 43. 50. Gf

\section{INTRODUCTION}

Recent office automation equipment is generally designed for high-density packaging and dissipates much heat. It has, therefore, air from blowers, fans and a duct leading to outside of the equipment. Especially, for high speed flow in the duct, additional turbulent noise uncoherent from the original noise can be produced. This decreases the estimation precision of an Adaptive Digital Filter when ANC is applied to the duct.

Ordinary countermeasures against the problem can mainly be divided into two ways. One is the taking only the coherent components as the primary noise with plural detection sensors. ${ }^{1}$ The other is the putting the meshes ${ }^{2}$ or the grid $^{3)}$ in the duct for flow rectification. The use of the meshes is suitable because of its simplicity, low cost, and well proben principles. ${ }^{4,5)}$

Though criteria about the effect of the meshes have already existed, ${ }^{4,5)}$ the relationship between the criteria and the effect of ANC has not been clarified. In this report, the relationship between them have been examined. Furthermore, a suitable position for settling the meshes, the effective flow range for adapting the meshes, the noise control effect due to the meshes, and a comparison with the meshes with sound absorbent material on the sensors to reduce the additional noise, have been reported.

\section{EQUIPMENT USED IN EXPERIMENT}

Figure 1 shows the layout of the equipment which imitates the cooling system of a large printer in the experiment. Details are as shown below.

- Maximum air velocity at outlet $\quad 12.0 \mathrm{~m} / \mathrm{s}$

- Reynolds number inside the duct $\quad 1.0 \times 10^{5}$

- Pressure loss factor $\zeta$ at the connection of the duct 0.59

- Algorithm Improved filtered- $X^{6)}$

- DSP 5 chips of Fujitsu MB86224 (75 ns $)^{7)}$ 


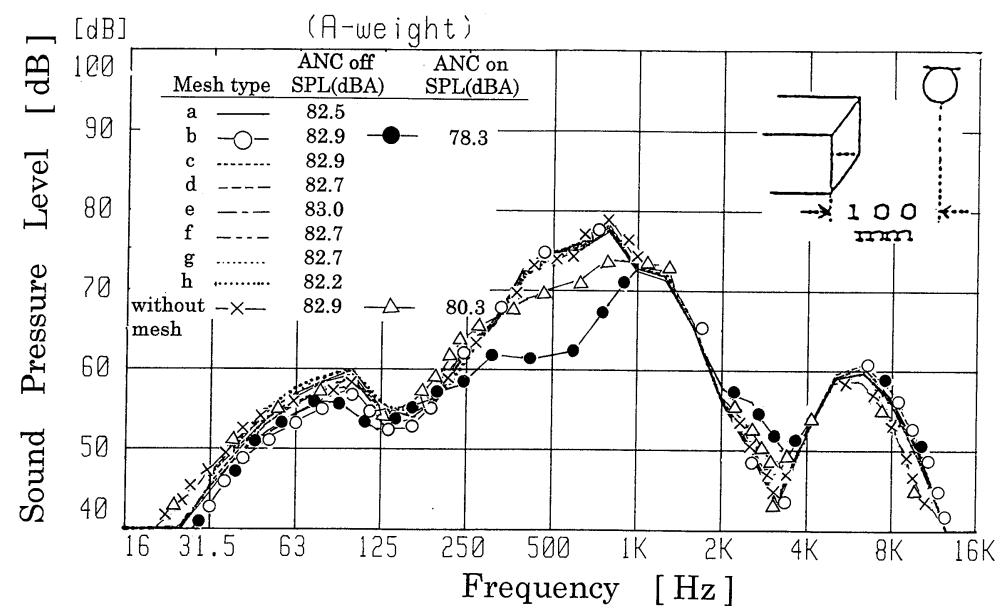

Fig. 3 A-weighted frequency characteristic at each mesh. $D=50 \mathrm{~mm}$, flow velocity of $12 \mathrm{~m} / \mathrm{s}$.

neous factors were absolutely negligible because wider variation of the positions in the case of $D=0$ to $250 \mathrm{~mm}$ were not critical for deterioration of the coherence function than the narrower some in the case of $D=250$ to $300 \mathrm{~mm}$.

\section{NOISE CONTROL EFFECT DUE TO MESHES}

Figure 3 shows frequency characteristics measured at a point $100 \mathrm{~mm}$ from the duct outlet. The maximum static pressure of the blower is so high (60 $\mathrm{mm} \mathrm{H}_{2} \mathrm{O}$ ) that the flow speed of $12 \mathrm{~m} / \mathrm{s}$ could be maintained regardless of the variety of mesh. Actually, mean error accompanying each measured flow speed, scattered as the same extent as the slight changes of the flow speed caused by the variety of meshes.

The noise reduction effect by meshes without ANC were under $200 \mathrm{~Hz}$ for mesh $\mathrm{b}$ (see the plots $O$ in Fig. 3). The reduction at around 3 to $4 \mathrm{~dB}$ was possible in comparison with the case with no meshes (see the plots $\times$ in Fig. 3), even without ANC. Furthermore, a reducible sound pressure level (SPL) of around $13 \mathrm{~dB}$ at $500 \mathrm{~Hz}$ was accomplished with ANC (see the plots $\bullet$ in Fig. 3).

\section{THE EFFECT OF ANC WITH MESHES}

6.1 Relationship between Effect and Type of Meshes

ANC was applied, when each of different mesh was set inside the duct in turn. The effect of ANC was measured after adapting coefficients of all digi-

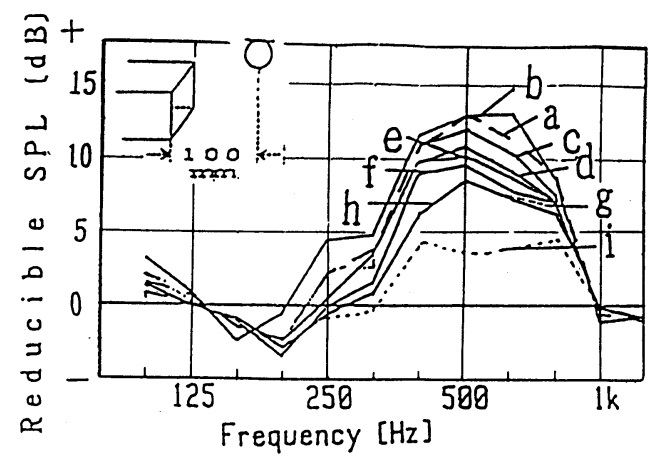

Fig. 4 Reducible SPL with ANC at each mesh. A-weighted characteristic, $D=50 \mathrm{~mm}$.

tal filters. The flow speed of the blowers, and the amplifier gain for sensors and a secondary source were all kept constant so that the measured data could be compared despite different rectifying meshes. Figure 4 shows the effect of ANC at each mesh measured at a position $100 \mathrm{~mm}$ from the duct exhaust port under a flow velocity of $12 \mathrm{~m} / \mathrm{s}$. The results may be summarized as follows. First, reducible SPL depends more on the numerical aperture than the size of mesh hole. Second, the smaller the mesh holes, the more reducible the SPL, is for almost the same numerical aperture. Finally, these factors also reflect the disturbance velocity attenuation factor which decides the reducible SPL.

\subsection{Flow Range for Adapting Meshes for ANC}

The flow range for adapting the meshes has been 


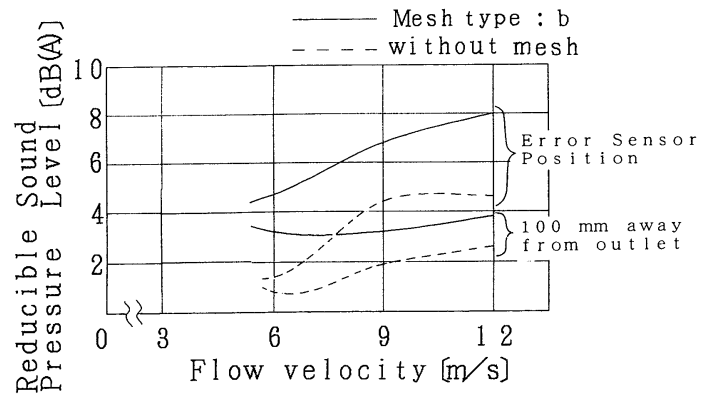

Fig. 5 Effect of change in flow velocity on ANC $(D=50 \mathrm{~mm})$.

described in Fig. 5. The data was measured at each flow speed which was set with voltage supplied to blower, using mesh type $b$ after setting the gain of the amplifier for the sensors and secondary source, and each coefficient of all digital filters so that measurement data could be compared despite different flow speeds. The effect of ANC deteriorated at $6 \mathrm{~m} / \mathrm{s}$ because dominant periodic noise synchronized with blower rotation corresponded to the $1 \mathrm{kHz}$ of cut-on frequency.

\section{THICKER SOUND ABSORBENT MATERIAL ON SENSORS VS. MESHES}

Two selections must be realistic for gaining high coherency under these experimental condition without the evident loss in the air pressure. One is use of the sound absorbent material of more than $20 \mathrm{~mm}$ in thickness, on the surface of sensors without the rectifying meshes, and the other is the use of the rectifying meshes with the sound absorbent material of just $20 \mathrm{~mm}$ in thickness, on the surface of sensors. Both methods were compared. First, flow speed was set as $12.0 \mathrm{~m} / \mathrm{s}$ without the rectifying meshes, and the numerical aperture of the duct cross-section was defined as $100 \%$. Next, the thickness of sound absorbent material on the sensors was gradually increased like these.

\begin{tabular}{ccc}
\hline $\begin{array}{c}\text { Thickness of } \\
\text { sound absorbent } \\
\text { material }\end{array}$ & Flow velocity & $\begin{array}{c}\text { The numerical } \\
\text { aperture of duct } \\
\text { cross-section }\end{array}$ \\
\hline $20 \mathrm{~mm}$ & $12.0 \mathrm{~m} / \mathrm{s}$ & $100.0 \%$ \\
$30 \mathrm{~mm}$ & $13.0 \mathrm{~m} / \mathrm{s}$ & $92.3 \%$ \\
$40 \mathrm{~mm}$ & $14.2 \mathrm{~m} / \mathrm{s}$ & $84.6 \%$ \\
\hline
\end{tabular}

Figure 6 shows the A-weighted reducible SPL with ANC for various thickness of sound absorbent

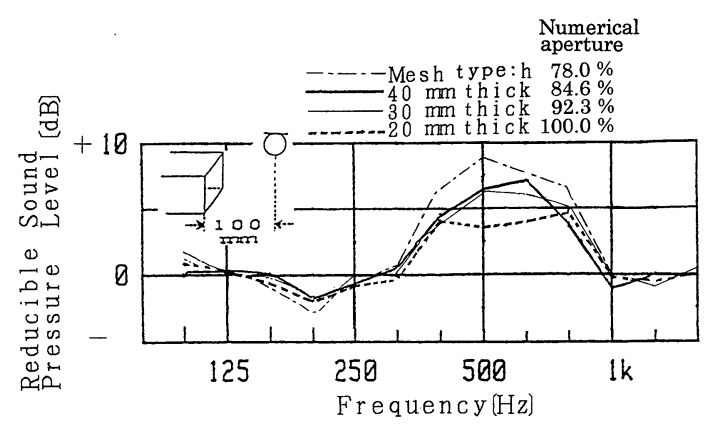

Fig. 6 A-weighted reducible SPL with ANC at each thickness of sound absorbent material on the surface of sensors.

material on the surface of sensors, and for 3 mesh (type h) with a 20-mm-thick sound absorbent material (plotted with same data as in Fig. 4). It is unnecessary to increase the thickness of sound absorbent material to more than $30 \mathrm{~mm}$ since this reduces the numerical aperture of the cross-section.

\section{CONCLUSION}

$13 \mathrm{~dB}$ of noise control effect (measured $100 \mathrm{~mm}$ from the duct outlet) was obtained at $500 \mathrm{~Hz}$ with the ANC system with meshes, applied to an exhaust duct with a flow velocity of $12.0 \mathrm{~m} / \mathrm{s}$ (Reynolds number of $\left.1.0 \times 10^{5}\right)$. The effect of ANC depends on the disturbance velocity attenuation factor of the meshes, which gives a measure of the rectifying effect. The mesh should not be installed closer to the detection sensor than half the diameter of the duct because this would destroy the point of adopting the meshes.

The noise reduction effect without ANC, which the meshes bring by themselves, was under $200 \mathrm{~Hz}$ by the use of an ideal mesh. At around 3 to $4 \mathrm{~dB}$ (measured $100 \mathrm{~mm}$ from the duct outlet), the effect was observed in comparison with the result for no meshes.

The mesh is more effective than the use of thicker sound absorbent materials on the sensors, although the numerical aperture of duct cross-section can be decreased both. The effective flow range worth for adapting the meshes were observed at flow speed of more than $6 \mathrm{~m} / \mathrm{s}$.

\section{REFERENCES}

1) I. C. Shepherd, R. F. LaFontaine, and A. Cabelli, "Active attenuation in turbulent flow ducts," Proc. 


\section{T. HOSHINO et al. : USE OF MESHES FOR ACTIVE NOISE CONTROL}

Inter-Noise '84 Honolulu, 497-500 (1984).

2) K. Nagayasu and S. Suzuki, "Relation between performance of active noise control and spatial coherence of flow noise," Proc. Autumn Meet. Acoust. Soc. Jpn. 643-644 (1994) (in Japanese).

3) T. N. Christenson, "Active noise cancellation in a duct with highly turbulent air flow," Noise-Con '96 Seattle, 369-374 (1996).

4) G. I. Taylor and G. K. Batchelor, Q. J. Mesh. Appl. Math. 2(1), 1 (1949).

5) L. F. G. Simmons and C. F. Cowdrey, ARC, R\&M,
No. 2276 (1945).

6) K. Fujii and J. Ohga, "A study on stability of the filtered-x algorithm," Tech. Rep. IEICE EA92-72, 25-32 (1992) (in Japanese).

7) T. Hoshino, A. Yamaguchi, H. Furuya, T. Ohashi, K. Fujii, and J. Ohga, "Application of active noise control for small-sized electronic equipment," Proc. Inter-Noise '94 Yokohama, 1409-1412 (1994).

8) H. Tanaka, "Kannairyu ni okeru teikoutai ni yoru seiryu kouka," JSME Tech. Rep. 41-346, 1802-1809 (1975) (in Japanese). 